\title{
A Systematic Review About Use of TensorFlow for Image Classification and Word Embedding in the Brazilian Context
}

\author{
Thereza Patrícia Pereira Padilha ${ }^{1}$, Lucas Estanislau Alves de Lucena $^{1}$ \\ ${ }^{1}$ Federal University of Paraiba - UFPB, Center of Applied Science and Education, Rio Tinto - PB, Brazil
}

Reception date of the manuscript: 31/05/2020

Acceptance date of the manuscript: 09/06/2020

Publication date: $12 / 06 / 2020$

\begin{abstract}
A great deal of data are available on the Internet, and it is possible to extract any type of implicit knowledge using Artificial Intelligence (AI) tools to support decision making. The open-source TensorFlow framework, developed by the Google Brain Team in 2015, is, presently, the most used tool for several AI applications, such as image classification, word embedding, and chatbot development. This paper presents results of a systematic review of the use of the TensorFlow framework for image classification and word embedding applications written in Portuguese language and in the Brazilian context. We used Google Scholar as Academic Search Engine and 90 were retrieved initially. However, just 12 were remained for reading and obtaining of the main information. Title, publication year, used domain, type of application and covered scope were collected from papers retrieved to accelerate studies in the AI area and to disseminate the potential of this framework for emerging challenges.
\end{abstract}

Keywords-Systematic Review, TensorFlow framework, Artificial Intelligence Applications.

\section{INTRODUCTION}

$\mathrm{T}$ he responsible area to process a high volume of data for implicit knowledge acquisition is Artificial Intelligence (AI) $[1,2]$. AI is an area of Computer Science that presents several techniques and algorithms in the development of intelligent projects, allowing similar decision making to that of human beings [3]. For example, when you open the YouTube website or app, the AI implemented recommends some similar videos based on previously searched or watched videos. The most popular term in AI area today is Machine Learning, which is a method of data analysis that automates the analytical model's construction. Some Machine Learning applications include natural language processing, search engines, medical diagnostics, bioinformatics, speech recognition, handwriting recognition, image recognition, robot locomotion, and forecasting systems [4].

In the literature, we can find several frameworks for Machine Learning applications, such as TensorFlow (Google's framework) [5], Azure (Microsoft) [6], and AWS [7]. TensorFlow, for example, gained much popularity in the last years among developers who intend to apply machine learning to emerging challenges, such as preparing teachers to use intelligent tools in order to anticipate interventions, to provide personalized and real-time feedbacks, and so on. Thus, this paper aims to present results of a systematic review to identify and analyze Brazilian papers that used Google's AI framework, known as TensorFlow, for image classification and word embedding applications.

This paper is organized as follows: in section II, concepts and two kinds of applications (image recognition and word embedding) used with TensorFlow framework are presented. Section III presents the methodology employed to perform this systematic review. In section IV, the results are displayed and discussed, and, finally, in section $\mathrm{V}$ the conclusions are presented.

\section{TENSORFLOW FRAMEWORK AND APPLICATIONS}

TensorFlow is an open-source library developed by the Google Brain Team (AI research group at Google) in 2015, written in $\mathrm{C}++$, for Artificial Intelligence applications. TensorFlow is multiplatform (Windows, MacOS, and Linux) and can be run on CPU (Central Processing Unit), GPU (Graphics Processing Unit) and TPU (Tensor Processing Units) [5]. Currently, it is considered the most used software for Machine Learning and Deep Learning applications [8]. Google, Intel, Uber, Airbnb, and DropBox, for example, are some companies that already use it in their solutions.

The differential of this framework is the use of data flow graphs, with each node representing a mathematical operation and each edge representing a data matrix (multidimensional tensor). Its main feature is the ability to quickly generate a trained predictive model, eliminating the need to reimplement it and with high precision.

There are a variety of applications that TensorFlow can be used for, such as image classification, word embedding, recommendation systems, stock prediction, and chatbot building. However, in this work, the systematic review focused only on applications such as image recognition and word embedding because they are the most used by TensorFlow. In addition, these two types of applications have transformed basic everyday actions such as unlocking a mobile screen through facial recognition or writing a 
faster message on WhatsApp or Email by proposing a set of words according to the context presented.

Image classification applications serve, for example, to unlock a cell phone screen, to find a suspect, or even to identify an unknown object. Basically, the image classification process (for people, animals, objects, places, etc.) uses algorithms that search, compare, and try to find relationships among a given image (shown on the camera or not) and other stored images in a database.

Word embedding applications are other tasks that can be implemented by TensorFlow. For example, when you are writing a message, this type of application suggests some words according to the meaning presented, reducing the user's effort and time.

\section{METHODOLOGY}

A systematic review is a form of research that uses literature on an established topic as a data source. This type of investigation provides a summary of the evidence related to a specific intervention strategy through the application of explicit and systematic methods of searching, critical appraisal, and synthesis of the selected information. In this work, the systematic review model proposed by [9] was adapted, which consisted of 3 phases: (1) Input - definition of one or more research questions, search string, search engine, and inclusion and exclusion criteria; (2) Processing - search for papers according to criteria and the defined search location; and (3) Output - list of filtered papers with yours relevant information.

\section{RESULTS}

\section{a. Input Phase}

This work attempts to answer the following research questions:

- Primary question:

- What are the most recent papers related to TensorFlow written in Portuguese?

- Secondary questions:

- What are the most recent papers related to TensorFlow for Image Classification application written in Portuguese?

- What are the most recent papers related to TensorFlow for Word Embedding application written in Portuguese?

A search string is a string of characters used to symbolize words or terms in order to do a search on an Academic Search Engine (MBA). This systematic review was limited to only Brazilian scientific works, with the search string being searched in Portuguese, with the purpose of verifying the progress of research on this topic in Brazil. From the previously defined questions, the search string used was:

((“TensorFlow" OR "Tensorflow”) AND ("classificação de imagens" OR “incorporação de palavras"))
The search source chosen was Google Scholar (https://scholar.google.com/), because it has many papers from different areas of knowledge in several languages, is free and well known, allows searches for dates, and creates alerts and filters.

The inclusion (IC) and exclusion (EC) criteria defined for this systematic review are shown in Table 1.

TABLE 1: INCLUSION AND EXCLUSION CRITERIA.

\begin{tabular}{l|l}
\hline \hline Inclusion Criteria & Exclusion Criteria \\
\hline \hline $\begin{array}{l}\text { IC1 - Papers published between } \\
2010 \text { and } 2019\end{array}$ & EC1 - Duplicated \\
\hline $\begin{array}{l}\text { IC2 - Papers available for } \\
\text { download }\end{array}$ & $\begin{array}{l}\text { EC2 - Papers have at least a } \\
\text { minimum of 4 pages to a } \\
\text { maximum of 20 pages }\end{array}$ \\
\hline & $\begin{array}{l}\text { EC3 - Papers do not related to } \\
\text { Image Classification or Word } \\
\text { Embedding }\end{array}$ \\
\hline \hline
\end{tabular}

\section{b. Processing Phase}

Using the academic search engine Google Scholar and the search string mentioned previously, 90 documents were found. Table 2 illustrates, in more details, the number of documents remaining after the application of IC1, IC2, $\mathrm{EC} 1, \mathrm{EC} 2$, and EC3 criteria.

TABLE 2: APPLICATION OF INCLUSION AND EXCLUSION CRITERIA.

\begin{tabular}{l|l}
\hline \hline Inclusion/Exclusion Criteria & \# of Documents \\
\hline \hline Initial List & 90 \\
\hline IC1 & 78 \\
\hline IC2 & 74 \\
\hline EC1 & 0 \\
\hline EC2 & 61 \\
\hline EC3 & 1 \\
\hline Final List & 12 \\
\hline \hline
\end{tabular}

The IC1 criterion (papers between 2010 and 2019) kept 78 of the 90 documents recovered. The EC2, which corresponds to the number of pages, was the one that had the greatest impact on filtering, since it excluded 61 documents that, basically, were dissertations or theses. After applying the criteria, only 12 papers remained to be analyzed, 10 of which focused on Image Classification and 2 on Word Embedding.

\section{c. Output Phase}

Table 3 presents a set of basic information of filtered papers, authors' names, title of the paper, publication year, used domain, type of application (Word Embedding or Image Classification) and the scope of the content covered (Theory, Test and/or Implementation). 


\begin{tabular}{|c|c|c|c|c|c|c|}
\hline \# & Authors & Tittle & Year & Domain & Application & Coverage \\
\hline 1 & Pedro A. Lelis; Filipe I. Fazanaro; J. R. Sato & $\begin{array}{l}\text { Análise da influência dos hiperparâmetros no treinamento de word embeddings } \\
\text { para a língua portuguesa }\end{array}$ & 2018 & $\begin{array}{l}\text { Portuguese } \\
\text { Language }\end{array}$ & $\begin{array}{l}\text { Word } \\
\text { Embedding }\end{array}$ & Test \\
\hline 2 & Rafael de Sá; Kaio Ribeiro; André Aranha & $\begin{array}{l}\text { Detecção e reconhecimento de faces, objetos e ações em tempo real em vídeo com } \\
\text { raspberry pi através de uma rede neural convolucional }\end{array}$ & 2018 & Home Security & $\begin{array}{l}\text { Image } \\
\text { Classification }\end{array}$ & Test \\
\hline 3 & Andre G. C. Pacheco & Classificação de espécies de peixe utilizando redes neurais convolucional & 2016 & Fishing & $\begin{array}{l}\text { Image } \\
\text { Classification }\end{array}$ & Test \\
\hline 4 & Amanda C. Spolti & Classificação de vias através de imagens aéreas usando deep learning & 2018 & Traffic & $\begin{array}{l}\text { Image } \\
\text { Classification }\end{array}$ & Implementation \\
\hline 5 & Raí G. Carvalho; Leticia T. M. Zoby & Convolutional neural networks for leaf disease classification & 2018 & Agriculture & $\begin{array}{l}\text { Image } \\
\text { Classification }\end{array}$ & Test \\
\hline 6 & Vinicius E. Martins & Deep learning para classificação de imagens & 2018 & Livestock & $\begin{array}{l}\text { Image } \\
\text { Classification }\end{array}$ & Theory \\
\hline 7 & Marcelo S. de Melo & Dual Scaling: Uma implementação em gpu com o TensorFlow & 2018 & Prograamming & $\begin{array}{l}\text { Image } \\
\text { Classification }\end{array}$ & Implementaion \\
\hline 8 & Gabriel de C. Vasconcelos & $\begin{array}{l}\text { Identificação da praga bicho-mineiro em plantações de café usando imagens } \\
\text { aéreas e deep learning }\end{array}$ & 2019 & Agriculture & $\begin{array}{l}\text { Image } \\
\text { Classification }\end{array}$ & Implementaion \\
\hline 9 & $\begin{array}{l}\text { Flávio H. D. Araújo; Allan C. Carneiro; Romuere R. V. Silva; } \\
\text { Fátima N. S. Medeiros; Daniela M. Ushizima }\end{array}$ & Redes neurais convolucionais com TensorFlow: teoria e prática & 2017 & Human Health & $\begin{array}{l}\text { Image } \\
\text { Classification }\end{array}$ & $\begin{array}{c}\text { Test and } \\
\text { Implementation }\end{array}$ \\
\hline 10 & Maxwell M. Ribeiro; Samuel S. Guimarães & Redes Neurais utilizando TensorFlow e Keras & 2018 & Programming & $\begin{array}{l}\text { Image } \\
\text { Classification }\end{array}$ & $\begin{array}{c}\text { Test and } \\
\text { Implementation }\end{array}$ \\
\hline 11 & $\begin{array}{l}\text { Humberto da S. Neto; Clebeson C. dos Santos; Mariana R. } \\
\text { Fernandes }\end{array}$ & Transfer Learning for Facial Emotion Recognition & 2018 & Human Emotion & $\begin{array}{l}\text { Image } \\
\text { Classification }\end{array}$ & Test \\
\hline 12 & Rafael A. S. Andrade; Franciny M. Barreto; Esdras L. Bispo Jr. & $\begin{array}{l}\text { Uso de mineração de dados para o auxílio de produção de material didático em } \\
\text { disciplinas de algoritmos }\end{array}$ & 2019 & Education & $\begin{array}{c}\text { Word } \\
\text { Embedding }\end{array}$ & $\begin{array}{c}\text { Test and } \\
\text { Implementation }\end{array}$ \\
\hline
\end{tabular}




\section{Conclusions}

This paper presented a systematic review of papers written in Portuguese (Brazilian) about image classification and word embedding applications with the TensorFlow framework. After a systematic search, 12 papers were retrieved in this area, 10 being for image classification and 2 for word embedding applications.

This revealed that there are many domains for the use of these applications such as pest control in plants and emotional recognition. We recommended the papers "Use of Data Mining to Aid the Production of Didactic Material in Algorithmic Disciplines" and "Classification of Pathways through Aerial Images using Deep Learning" for reading about word embedding and image classification, respectively, because they have presented, in more details, how to use TensorFlow framework to solve emerging challenges.

In order to obtain more relevant papers, we suggest extending the search string, allowing papers written in English, and using other research sources, such as ACM or IEEE.

\section{ACKNOWLEDGMENT}

We thank the Lecturer Carlos Valdes of the Georgia Tech Language Institute for his special English review.

\section{REFERENCES}

[1] W. L. J. Teixeira, "Big Data, Jornalismo Computacional e Data Journalism: estrutura, pensamento e prática profissional na Web de dados," Estudos em Comunicação, no. 12, pp. 207-222, 2012.

[2] S. Loh, BI na era do big data para cientistas de dados: indo além de cubos e dashboards na busca pelos porquês, explicações $e$ padrões, kindle edition, Porto Alegre, RS, 2014.

[3] A. Bottini and A. Laurentini, "Experimenting with non instructive motion capture in a virtual environment," The Visual Computer, no. 17, pp. 14-29, 2001.

[4] M. J. V. Amorim, D. Barone and A. U. Mansur "Técnicas de Aprendizado de Máquina Aplicadas na Previsão de Evasão Acadêmica," in Proc. XIX Simpósio Brasileiro de Informática na Educação, Fortaleza, CE, Brasil, 2008, pp. 1-9.

[5] TensorFlow. An end-to-end open source machine learning platform. (2019, Set. 23). Available: https://www.tensorflow.org/

[6] Azure Machine Learning. Enterprise-grade machine learning service to build and deploy models faster. (2020, May. 27). Available: https://azure.microsoft.com/en-us/services/machinelearning/

[7] Machine Learning on AWS. Putting machine learning in the hands of every developer. (2020, May. 27). Available: https://aws.amazon.com/machine-learning/

[8] 10 Most Popular Machine Learning Software Tools in 2020 (updated). (2020, Jun. 8). Available: https://towardsdatascience.com/10-most-popular-machinelearning-software-tools-in-2019-678b80643ceb

[9] E. C. Conforto, D. C. Amaral and S. L. D. Silva "Roteiro para revisão bibliográfica sistemática: aplicação no desenvolvimento de produtos e gerenciamento de projetos," in Proc Congresso
Brasileiro de Gestão de Desenvolvimento de Produtos, Porto Alegre, RS, Brasil, 2011, pp. 1-12. 